\title{
INTERFACES ENTRE A FORMAÇÃO DE PROFESSORES E O BEM/MAL-ESTAR NA DOCÊNCIA NA EDUCAÇÃO BÁSICA
}

\author{
INTERFACES ENTRE LA FORMACIÓN DE PROFESORES Y EL BIEN/MALESTAR \\ EN LA ENSEÑANZA EN LA EDUCACIÓN BÁSICA
}

\author{
INTERFACES BETWEEN TEACHER FORMATION AND WELFARE/MALAISE IN \\ BASIC EDUCATION TEACHING
}

\author{
Rosa Carine Menezes de MATTOS ${ }^{1}$ \\ Jordana Wruck TIMM ${ }^{2}$
}

RESUMO: O artigo enfatiza a relação da formação de professores com a questão do bem e mal-estar docente na Educação Básica e objetiva compreender quais são os impactos da docência na saúde dos profissionais da educação, especialmente no que tange à possibilidade de satisfação das necessidades psicológicas básicas dos indivíduos (autonomia, competência e pertencimento). A abordagem teórica e metodológica utilizada na elaboração do artigo contempla pesquisa bibliográfica, com viés qualitativo. A análise desses referenciais permite constatar que a formação de professores pode contribuir de modo decisivo para a realização profissional, engendrando a necessária competência, comprometimento e equilíbrio entre vida pessoal e a atividade laboral, fatores imprescindíveis para o bem-estar dos professores. Por meio dessa abordagem, espera-se salientar a relevância da qualificação permanente dos processos formativos e de políticas públicas que assegurem condições dignas de vida e de exercício da docência.

PALAVRAS-CHAVE: Formação de professores. Bem e mal-estar docente. Necessidades psicológicas básicas. Educação básica.

RESUMEN: El artículo enfatiza la relación de la formación docente con el tema del bienestar y malestar docente en la Educación Básica y tiene como objetivo comprender los impactos de la docencia en la salud de los profesionales de la educación, especialmente en lo que se refiere a la posibilidad de satisfacer las necesidades psicológicas básicas de los individuos (autonomía, competencia y pertenencia). El enfoque teórico y metodológico utilizado en la elaboración del artículo incluye la investigación bibliográfica, con un sesgo cualitativo. El análisis de estas referencias muestra que la formación del profesorado puede contribuir decisivamente al logro profesional, generando la competencia, el compromiso y el equilibrio necesarios entre la vida personal y la actividad laboral, factores esenciales para el bienestar de los profesores. A través de este enfoque, se espera enfatizar la relevancia de la

${ }^{1}$ Universidade Regional Integrada do Alto Uruguai e das Missões (URI), Frederico Westphalen - RS - Brasil. Mestranda no Programa de Pós-Graduação em Educação. Escola de Educação Básica (URI), São Luiz Gonzaga - RS - Brasil. Professora titular e Coordenadora Pedagógica. ORCID: https://orcid.org/0000-0001-9528-6520. E-mail: rosacarine@gmail.com

${ }^{2}$ Universidade Regional Integrada do Alto Uruguai e das Missões (URI), Frederico Westphalen, Frederico Westphalen - RS - Brasil. Bolsista de Pesquisa (PNPD/CAPES) e professora Colaboradora no Programa de PósGraduação em Educação. ORCID: https://orcid.org/0000-0002-4445-1909. E-mail: jordanawruck@hotmail.com 
cualificación permanente de procesos de formación y políticas públicas que aseguren condiciones de vida dignas y práctica docente.

PALABRAS CLAVE: Formación de profesores. Bien y malestar docente. Necesidades psicológicas básicas. Educación básica.

ABSTRACT: The article emphasizes the relationship between teacher education and the issue of teacher welfare and malaise in Basic Education and aims to understand the impacts of teaching on the health of education professionals, especially regarding the possibility of meeting basic psychological needs of individuals (autonomy, competence and belonging). The theoretical and methodological approach used in the elaboration of the article includes bibliographical research, with a qualitative bias. The analysis of these references shows that teacher education can decisively contribute to professional achievement, engendering the necessary competence, commitment and balance between personal life and work activity, essential factors for the well-being of teachers. Through this approach, it is expected to highlight the relevance of the permanent qualification of formative processes and public policies that ensure dignified living conditions and teaching practice.

KEYWORDS: Teacher formation. Teacher welfare and malaise. Basic psychological needs. Basic education.

\section{Introdução}

Neste texto discute-se as interfaces entre a formação de professores e a questão do bem e mal-estar docente, problematizando os impactos do exercício da docência na saúde e na qualidade de vida dos educadores. E, ainda, tece-se uma reflexão sobre a importância da satisfação das necessidades psicológicas básicas para que os indivíduos se mantenham saudáveis e satisfeitos com a profissão exercida. Assim, espera-se responder à problemática: Quais os impactos da docência no bem/mal-estar dos professores da Educação Básica e quais as possibilidades de a formação docente contribuir para a saúde e a qualidade de vida dos profissionais da educação?

Com base na definição de Gil (2008), considera-se a pesquisa bibliográfica o estudo realizado a partir de material já elaborado (livros e artigos). A pesquisa bibliográfica, de cunho qualitativo, busca fundamentação nos escritos de autores considerados referências nos temas da formação de professores e do bem/mal-estar docente, dentre os quais destacam-se: Pimenta (2005), Contreras (2002), Nóvoa (2012; 1995) e Tardif (2002), no âmbito da formação de professores; Esteve (1999) e Fossati, Guths e Sarmento (2013), no que concerne ao bem e mal-estar docente. A partir de tal abordagem, objetiva-se compreender quais são os impactos da docência na saúde dos profisssionais da educação, especialmente no que tange à 
possibilidade de satisfação das necessidades psicológicas básicas (NPB) dos indivíduos, as quais são relevantes para a constituição do sentimento de autonomia, de competência e de pertencimento.

Vale sublinhar que o professor é um dos elementos centrais no processo de ensino e aprendizagem, principalmente na Educação Básica. Tal processo passa por intensas transformações ao longo do tempo, sendo impactado pelas especificidades de cada momento histórico e pelas peculiaridades das distintas sociedades humanas. Em especial, agora, em que o conhecimento adquire centralidade, o processo de ensinar e aprender torna-se significativo e demanda na transformação nas percepções sobre o papel do professor, buscando-se a valorização deste profissional como mediador na construção e na sistematização do saber.

Com base nessas ponderações, observa-se a necessidade de aprofundar as pesquisas sobre a formação de professores e suas relações com a questão do bem e mal-estar docente. A partir desse estudo, espera-se pensar em caminhos para assegurar o bem-estar dos educadores no espaço escolar, minimizando os impactos das variáveis percebidas como causadoras de mal-estar entre os docentes, apostando na convicção de que profissionais realizados e satisfeitos realizam um trabalho qualificado e conseguem manter-se saudáveis, especialmente ao sentir-se autônomos, competentes e pertencentes ao coletivo da escola e da educação.

Diante disso, o presente artigo, em seu percurso de construção, apresenta além do resumo e da introdução, a análise da temática em dois eixos: 1- Bem e Mal-Estar Docente, em que apresenta-se sinteticamente o entendimento a respeito das noções de bem-estar e malestar dos profissionais da educação; 2 - A Configuração do Bem e Mal-Estar Docente: A Formação de Professores e as Necessidades Psicológicas Básicas, no qual são delineadas as interfaces entre os processos formativos e a manutenção da saúde e do bem-estar dos professores, por meio da satisfação das necessidades psicológicas básicas. A seguir, constam as considerações finais e as referências bibliográficas que embasam o estudo.

\section{Bem e mal-estar docente}

A reflexão a respeito do bem e mal-estar docente na contemporaneidade requer, em primeira instância, a retomada dos sentidos da docência. Tardif (2002) define o professor como um sujeito que possui conhecimentos e um saber-fazer provenientes da sua própria atividade e a partir dos quais ele a estrutura e a orienta. Para o autor, compreender a identidade docente implica em considerar a subjetividade do professor. 
Analisando a complexidade da docência, Tardif (2002) destaca que o saber docente é múltiplo e pluriorientado, envolvendo saberes curriculares, disciplinas, exercício profissional e experiência pessoal. Os saberes curriculares relacionam-se com a proposição/seguimento de objetivos, organização dos conteúdos e métodos, compondo os programas escolares. Os saberes decorrentes da experiência resultam do trabalho cotidiano, da vivência de distintas situações pedagógicas, constituindo o saber e o saber-fazer.

Nas sociedades contemporâneas, o prestígio de uma profissão mede-se por sua visibilidade social. No caso dos educadores, Nóvoa (2012) defende que a sobrevivência da profissão depende da qualidade do trabalho interno nas escolas, mas também da sua capacidade de intervenção no espaço público da educação. Desse modo, a resolução dos impasses da educação e dos próprios professores vai além dos limites da escola, envolvendo a sociedade como um todo, a partir da valorização social da educação. A complexidade das sociedades atuais, a existência de um volume sem precedentes de informação ou a centralidade do conhecimento e da sua valorização social e econômica colocam os professores perante tarefas a que não podem responder sozinhos (NÓVOA, 2012).

É preciso avançar nas pesquisas relacionadas ao bem e mal-estar docente. Em especial, torna-se necessário refletir sobre a questão de forma mais abrangente, englobando a formação de professores e a profissionalização docente, aspectos negligenciados em grande parte dos estudos disponíveis a esse respeito. Contudo, na sociedade contemporânea, caracterizada pela fragmentação das relações e pelo esvaziamento de sentido da experiência humana. Como refere Bauman (2001), as diferentes esferas da sociedade contemporânea (vida pública, vida privada, relacionamentos humanos) transformam-se, esgarçando o tecido social, que perde a solidez e se liquefaz. Sendo assim, a modernidade líquida é o tempo do desapego, da provisoriedade e do processo da individualização; também da insegurança. $O$ interesse público é reduzido à curiosidade sobre as vidas privadas de figuras públicas e a arte da vida pública é reduzida à exposição pública das questões privadas e a confissões de sentimentos privados.

Especificamente no que tange aos professores, Esteve (1999) considera que o malestar docente se constitui como sentimento resultante dos efeitos permanentes de caráter negativo que afetam a personalidade do professor. Diante das excessivas exigências cotidianas, o profissional desenvolve sintomas que se manifestam nos planos biofisiológico, comportamental, emocional e cognitivo. Dentre alguns sintomas, destacam-se: desmotivação, senso de sobrecarga de trabalho, stress, irritabilidade e diminuição da autoestima. 
Esteve (1999) explica que o mal-estar na docência se relaciona com dois grupos de fatores. Na primeira ordem, constam os fatores internos à sala de aula, ligados às relações afetivas entre professor e aluno, ao longo do processo de ensino e de aprendizagem. $\mathrm{Na}$ segunda ordem, aparecem os fatores ambientais, externos à sala de aula e à escola e que interferem na eficácia da ação docente.

Fossati, Guths e Sarmento (2013) acrescentam fatores de terceira ordem relativos à própria pessoa do docente. Isto é, como seu modo de ser e de encarar a vida interferem diretamente em seu bem/mal-estar, em sua produção de sentido e em suas competências de resiliência. Os autores consideram que o contexto atual apresenta uma situação complexa, que amplia o sentimento de mal-estar. Todavia, é possível potencializar o bem-estar por meio da produção de sentido na docência, que parece ser uma categoria fundamental a ser contemplada. A trajetória de vida e a produção de sentido na vida dos professores se expressa em diferentes eixos no exercício da docência. Eles desenvolvem diferentes valores como estratégia de resposta aos desafios apresentados no percurso profissional.

Nesse sentido, na contemporaneidade vivenciada, os desafios postos aos educadores são múltiplos, entre eles destacam-se a diversidade de perfis de alunos, diferentes níveis de participação das famílias, burocracias institucionais, precarização da infraestrutura das escolas, flexibilização das legislações trabalhistas, desvalorização dos profisssionais da educação, dentre outros. Além destes desafios, a realidade é marcada pela instabilidade, caracterizando a modernidade líquida (BAUMAN, 2001), causando impacto nas relações sociais e trazendo a desestabilização e a superficialidade aos relacionamentos humanos. Todo esse contexto, pode representar obstáculos ao bem-estar docente e podem demandar transformações sociais e políticas que buscam garantir a dignidade e o protagonismo dos educadores.

Dworak e Camargo (2017) destacam que, na profissão docente, o mal-estar chega de forma silenciosa, com as pequenas tensões do dia a dia que vão se acumulando e dificultando o prazer de exercer as suas atividades, levando ao esgotamento físico e mental, os quais podem influenciar no desejo por lecionar. As autoras lembram que o espaço escolar, além de ser palco dessas dificuldades, pode ser, um ambiente motivador e favorecedor de alívio de tensões, buscando soluções coletivas. Se nos comprometemos em buscar o bem-estar, precisamos superar a individualização e a fragmentação, agindo como coletivo no enfrentamento das dificuldades que permeiam o exercício da docência. O bem-estar docente demanda políticas educacionais que incentivem a solidariedade e a cooperação, visando constituir ambientes de trabalho que sejam saudáveis e harmoniosos. 


\section{A configuração do bem-estar docente: a formação de professores e as necessidades psicológicas básicas}

Ao tematizar a questão da formação de professores, Pimenta (2005) ressalta a importância dos processos reflexivos. A autora descreve o sentido da expressão 'professor reflexivo', destacando a distinção da reflexão como atributo dos professores (adjetivo) e o movimento que se denominou professor reflexivo (conceito). Torna-se fundamental articular as práticas cotidianas e os contextos mais amplos, uma vez que o ensino se configura como prática social concreta.

Conforme Pimenta (2005), o professor reflexivo propõe práticas que superam o praticismo e os discursos sobre competências, voltados à tecnicização do trabalho dos professores e de sua formação. Em sua concepção, a teoria proporciona perspectivas de análise para o entendimento dos contextos históricos, sociais, culturais e organizacionais, também si mesmos enquanto profissionais, em que ocorrem as atividades docentes, buscando intervir e transformá-los. Portanto, é indispensável a crítica sobre as condições materiais.

Pimenta (2005) alerta, ainda, que são necessários avanços, para superar a fragmentação e o individualismo, passando-se a adotar ações coletivas que transformem as escolas em comunidades de aprendizagem. Nesse processo de transformação social e institucional, o professor apresenta-se como intelectual crítico. Para a autora, a reflexão é coletiva, buscando incorporar a análise da escola com relação aos contextos mais amplos e atribuir sentidos à reflexão. Trata-se, dessa maneira, de um compromisso emancipatório de transformação das diferenças sociais.

Nóvoa (1995) argumenta que os professores precisam possuir capacidades de (re)estruturação e de contextualização dos conhecimentos. A educação necessita realçar a história, o modo científico de pensamento, o uso disciplinado da linguagem, um conhecimento profundo das artes e da religião e a continuidade da empresa humana. O professor, ao ensinar, deve contar uma história sobre o conteúdo, oportunizando a compreensão do enredo.

Cabe, então, definir e redefinir a profissionalidade docente, contribuindo para que os professores adotem novas atitudes a nível individual e coletivo. Pessoa e profissional; ser e ensinar. As opções que temos que fazer, como professores, cruzam nossa maneira de ser e de ensinar, desvendam, em nossa maneira de ensinar, a nossa maneira de ser (NÓVOA, 1995).

Por meio de uma reelaboração permanente da identidade profissional, os professores poderão definir as ações que não podem mudar tudo, mas que podem mudar alguma coisa. Esta alguma coisa não é coisa pouca (NÓVOA, 1995). Os processos formativos necessitam, 
assim, capacitar os professores a buscarem as mudanças indispensáveis e a adotarem posturas de comprometimento com o conhecimento, com os alunos e com os contextos em que atuam.

Como ser esse educador comprometido, responsável é capaz de promover mudanças e, ao mesmo tempo, manter o bem-estar? Esta interrogação demanda a retomada das noções de bem e mal-estar docente, indagando sobre os fatores que garantem a saúde e a qualidade de vida dos educadores. Dentre esses fatores, destacam-se as necessidades psicológicas básicas: autonomia, competência e pertencimento.

A Organização Mundial da Saúde (OMS, 2006) define que a saúde é uma condição que extrapola a ausência de doenças, significando um estado complexo de bem-estar físico, mental e social. Por isso, o bem-estar implica no sentimento de autoeficiência, de autonomia, de competência, de autorrealização do potencial e emocional do indivíduo, na vida particular e no trabalho. Entre as teorias contemporâneas que podem subsidiar o estudo da motivação docente destaca-se a Self-Determination Theory (SDT) (DECI; RYAN, 2000; 2008), a qual entende que há elementos intrínsecos (interesses, crenças e escolhas próprias) e extrínsecos (pressões externas e resultados esperados) ao self agindo sobre a vontade e a determinação para as ações. Para a SDT, quanto mais as escolhas e comportamentos da pessoa se apoiam em elementos intrínsecos e na integração de princípios contextuais (extrínsecos) ao próprio sistema de valores mais a motivação assume caráter autônomo ou autodeterminado, o qual representa a base para a satisfação e o bem-estar psicológico (DAVOGLIO; TIMM; SANTOS; CONZATTI; 2017).

Com base no estudo de Davoglio et al. (2017), compreendemos que entre seus pressupostos fundantes, a SDT sustenta que o estudo sobre a motivação autodeterminada demandada pela consideração às Necessidades Psicológicas Básicas (NPB), definidas como necessidades inatas e universais, cuja satisfação é essencial para o bem-estar e o desenvolvimento saudável (DECI; RYAN, 2000). Postula que existem três NPB, agrupadas no senso de autonomia, no senso de competência e no senso de pertencimento (RYAN; DECI, 2002). O senso de autonomia se refere à flexibilidade e sensação de independência para agir de acordo com os próprios princípios, diante da integração de valores contextuais ao self, aprovados internamente. O senso de competência diz respeito à necessidade de se sentir eficaz, em causar ou obter resultados desejáveis e evitar resultados indesejáveis em ações que envolvem diferentes níveis de dificuldade, evidenciando o reconhecimento pelo sujeito das próprias capacidades e recursos. O senso de pertencimento/afiliação, por sua vez, tem seu foco na necessidade do sujeito se sentir conectado e apoiado por outras pessoas com quem 
convive, tendo a percepção de estar integrado e pertencente aquele contexto (RYAN; DECI, 2002).

José Contreras (2002) enfatiza a importância do entendimento amplo dos conceitos de autonomia e de profissionalismo, superando os discursos superficiais que utilizam esses termos como meros slogans. Para o autor, é preciso ultrapassar a noção de autonomia como mera possibilidade de agir sem condicionantes, quando o ensino se constitui como um trabalho irremediavelmente cheio de condicionantes, muitos dos quais plenamente justificáveis, dada a natureza social, pública da educação (CONTRERAS, 2002, p. 89).

Releva distinguir autonomia e independência, posto que um professor autônomo não é independente. Como explica Contreras (2002, p. 227), "não é possível falar de autonomia de professores sem fazer referências ao contexto trabalhista, institucional e social em que os professores realizam seu trabalho". Ao relacionar a autonomia e a profissionalidade, Contreras (2002) diferencia os modelos de professores: especialista técnico, profissional reflexivo e intelectual crítico. Sendo o modelo de racionalidade técnica restrito à solução instrumental de problemas pela aplicação de conhecimento teórico e técnico, a autonomia é ilusória, porque depende de diretrizes técnicas, apresenta insensibilidade diante dos dilemas e incapacidade de responder de modo criativo frente às incertezas.

Por seu turno, o profissional reflexivo apresenta competência profissional ligada à pesquisa/reflexão sobre a prática, com deliberação na incerteza acerca da forma moral ou educativamente correta de agir em cada caso. Em consonância com o modelo de professor reflexivo, a autonomia supõe a responsabilidade moral individual, considerando os diferentes pontos de vista. Demonstra equilíbrio entre a independência de juízo e a responsabilidade social, bem como a capacidade para resolver de modo criativo as situações-problema para a realização prática das pretensões educativas (CONTRERAS, 2002, p. 192). Em se tratando do professor como intelectual crítico, Contreras (2002) apresenta a seguinte descrição: 
Quadro 1 - Autonomia profissional

\begin{tabular}{|c|l|}
\hline $\begin{array}{c}\text { Modelo de professor } \\
\begin{array}{c}\text { Dimensões da } \\
\text { Profissionalidade do } \\
\text { professor }\end{array}\end{array}$ & \multicolumn{2}{|c|}{ Intelectual Crítico } \\
\hline $\begin{array}{c}\text { Obrigação moral } \\
\text { pelos valores de racionalidade, justiça e satisfação. }\end{array}$ \\
\hline $\begin{array}{c}\text { Compromisso com a } \\
\text { comunidade }\end{array}$ & $\begin{array}{l}\text { Defesa de valores para o bem comum (justiça, igualdade e } \\
\text { outros). Participação em movimentos sociais pela } \\
\text { democratização. }\end{array}$ \\
\hline Competência profissional & $\begin{array}{l}\text { Autorreflexão sobre as distorções ideológicas e os } \\
\text { condicionantes institucionais. Desenvolvimento da análise e } \\
\text { da crítica social. Participação na ação política transformadora. }\end{array}$ \\
\hline \multicolumn{2}{|c|}{ Concepção da autonomia profissional } \\
\hline
\end{tabular}

Autonomia como emancipação: liberação profissional e social das opressões. Superação das distorções ideológicas. Consciência crítica. Autonomia como processo coletivo (configuração discursiva de uma vontade comum), dirigido a transformação das condições institucionais e sociais do ensino.

Fonte: Adaptado de Contreras (2002, p. 192)

Com base nesta descrição, cabe compreender a autonomia como uma construção que engloba fatores pessoais e coletivos, buscando a emancipação por meio do conhecimento, e, consequentemente, a superação de opressões a partir da consciência crítica. O profissional possui liberdade para exercer sua prática, mas participa de um projeto coletivo de escola e de sociedade.

Nas palavras de Contreras (2002, p. 195):

[...] a relação entre autonomia e profissionalidade é, ao mesmo tempo, uma reivindicação da dignidade humana das condições trabalhistas dos professores e uma reivindicação de oportunidade para que a prática de ensino possa se desenvolver de acordo com determinados valores educacionais, valores que não sejam coisificados em produtos e estados finais, mas que atuem como elementos constitutivos, como orientadores internos da própria prática. Ou seja, a autonomia no ensino é tanto um direito trabalhista como uma necessidade educativa.

Autonomia e profissionalidade, articuladas à competência e ao senso de pertencimento, são fatores imprescindíveis para constituir o bem-estar docente. Professores que desenvolvem a autonomia, constroem a competência ético-política e técnico-científica, e que se sentem pertencentes ao coletivo da escola, possuem condições de enfrentar os desafios do cotidiano da docência e de mobilizar recursos psicológicos e racionais para superar obstáculos, mantendo-se saudáveis e satisfeitos com a profissão. 


\section{Considerações finais}

$\mathrm{Na}$ contemporaneidade, os desafios postos aos educadores são múltiplos: diversidade de perfis de alunos, diferentes níveis de participação das famílias, burocracias institucionais, precarização da infraestrutura das escolas, flexibilização das legislações trabalhistas, desvalorização dos profissionais da educação, dentre outros. Além disso, a realidade é marcada pela instabilidade, caracterizando a modernidade líquida, descrita por Bauman (2001), impactando nas relações sociais, trazendo a desestabilização e a superficialidade aos relacionamentos humanos.

Tais fatores representam obstáculos ao bem-estar docente e demandam transformações sociais e políticas que garantam a dignidade e o protagonismo dos educadores. Essas transformações não ocorrem de forma descontextualizadas e requerem ações no coletivo social. As estratégias voltadas à promoção do cuidado, da saúde e do bem-estar profissional precisam ser construídas pelo conjunto da sociedade, engajar os distintos segmentos da comunidade escolar na defesa de condições adequadas de trabalho e na consideração da educação como prioridade absoluta.

Daí decorre a necessidade de debate sobre as condições de trabalho e dos elementos que cooperam para a realização profisssional e a manutenção de saúde e qualidade de vida dos professores, bem como dos fatores que contribuem para o sofrimento e/ou adoecimento dos docentes. Estudar o bem e mal-estar docente é fundamental para a construção de estratégias que assegurem o reconhecimento da relevância social dos educadores e condições adequadas de exercício profissional. Dentre os fatores, merecem destaque as necessidades psicológicas: autonomia, competência e pertencimento.

A formação de professores adquire papel preponderante. Isso porque a cultura da profissão docente se fortalece a partir da competência e do comprometimento. Assegurar aos docentes a constante ressignificação de saberes e práticas é fundamental, tanto para o reconhecimento social da importância dos profissionais quanto para que se percebam como atores sociais engajados na construção de uma sociedade mais justa e solidária.

A garantia do bem-estar docente relaciona-se com a recuperação dos sentidos da cultura docente, lutando pela profissionalização, pela organização do trabalho docente, pela qualidade das relações sociais no contexto educacional, pela consistência dos processos formativos e pelo desenvolvimento profissional. Dessa maneira, a construção de um pacto social pela valorização dos docentes e pela melhoria das condições de trabalho e das relações interpessoais torna-se indispensável para assegurar a saúde e a qualidade de vida dos 
educadores. O que, em última instância, coopera para o avanço da sociedade como um todo, em decorrência da ampliação da qualidade da educação.

A partir das reflexões aqui esboçadas, corrobora-se a importância da ampliação dos estudos sobre a qualidade dos processos formativos e sobre o bem e mal-estar docente. Assim, pode-se construir referenciais consistentes para defender um pacto social em torno da educação, pautado no reconhecimento do papel do educador. Além disso, é preciso construir políticas e estratégias que permitam condições dignas de trabalho, autonomia no exercício da docência, comprometimento com a prática pedagógica, com os alunos e com o mundo e a competência técnico-científica, indispensável para, ao mesmo tempo promover a efetiva aprendizagem e a realização profissional.

AGRADECIMENTOS: CAPES.

\section{REFERÊNCIAS}

BAUMAN, Z. Modernidade líquida. Rio de Janeiro: Zahar, 2001.

CONTRERAS, J. A autonomia de professores. São Paulo: Cortez, 2002.

DAVOGLIO, T. R.; TIMM, J. W.; SANTOS, B. S.; CONZATTI, F. B. K. Necessidades psicológicas básicas: definições operacionais na docência universitária. ETD: Educação Temática Digital, v. 19, p. 510-531, 2017.

DECI, E. L.; RYAN, R. M. The "What" and "Why" of goal pursuits: human needs and the self-determination of behavior. Psychological Inquiry, 2000, v. 11, n. 04, p. 227- 268. Disponível em: http://goo.gl/cvu9Ek. Acesso em: 04 abr. 2016.

DECI, E. L.; RYAN, R. M. Self-determination theory: a macrotheory of human motivation, development, and health. Canadian Psychology, v. 49, n. 03, p. 182-185. ago. 2008.

DWORAK, A. P.; CAMARGO, B. C. Mal-Estar Docente: Um Olhar dos Professores. In: Anais... EDUCERE, 2017, p. 6913-6924.

ESTEVE, J. M. Mudanças sociais e função docente. In: António Nóvoa (Org.). Profissão professor. 2 ed., p. 93-124, Coleção Ciências da Educação. Porto, Portugal: Porto Editora, 1999.

FOSSATI, P.; GUTHS, H.; SARMENTO, D. F. Perspectivas para o Bem-estar na docência: trajetória de vida e produção de sentido. Revista Mal-estar e Subjetividade, Fortaleza - Vol. XII - No 1-2 - p. 271 - 298 - mar/jun 2013.

GIL, A. C. Como elaborar projetos de pesquisa. 4 ed. São Paulo: Atlas, 2008. 
NÓVOA, A. Diz-me como Ensinas, Dir-te-ei Quem és e Vice-Versa. In: FAZENDA, I. (org.). A pesquisa em educação e as transformações do conhecimento. Campinas (SP): Papirus, 1995.

NÓVOA, A. Devolver a formação de professores aos professores. Cadernos de Pesquisa em Educação - PPGE/UFES, Vitória, ES. a. 9, v. 18, n. 35, p. 11-22, jan./jun. 2012.

ORGANIZAÇÃO MUNDIAL DA SAÚDE (OMS). Constituição da Organização Mundial da Saúde. Documentos básicos, suplemento da $45^{\text {a }}$ edição, outubro de 2006. Disponível em espanhol em: https://www.who.int/governance/eb/who_constitution_sp.pdf. Acesso em: 16 jul. 2020.

PIMENTA, S. G. Professor Reflexivo: construindo uma crítica. In: PIMENTA, S. G.; GHEDIN, E. (orgs.). Professor Reflexivo no Brasil: gênese e crítica de um conceito - 3 ed. São Paulo: Cortez, 2005.

RYAN, R. M.; DECI, E. L. Overview of self-determination theory: an organismic dialectical perspective. In: DECI, Edward L.; RYAN, Richard. M. (Eds.). Handbook of selfdetermination research. Rochester, NY: University of Rochester Press. p. 03-33. 2002. Disponível em: http://goo.gl/7OgP4A. Acesso em: 04 abr. 2016.

TARDIF, M. Saberes docentes e formação profissional. Tradução de Francisco Pereira. Petrópolis: Vozes, 2002.

\section{Como referenciar este artigo}

MATTOS, R. C. M.; TIMM, J. W. Interfaces entre a formação de professores e o bem/malestar na docência na Educação Básica. Temas em Educ. e Saúde, Araraquara, v. 17, n. 00, e021014, 2021. e-ISSN 2526-3471. DOI: https://doi.org/10.26673/tes.v17i00.15196

Submetido em: $17 / 06 / 2021$

Aprovado em: 26/06/2021

Publicado em: 28/06/2021 